El 15 de octubre, día de la Facultad, nuestro vicedecano, el P. Eduardo PérezCotapos, hizo una evocación de la amplia labor académica de monseñor Antonio Moreno, quien fuera nuestro profesor y decano, recientemente fallecido. Agregamos a su semblanza una lista de sus publicaciones.

\title{
Monseñor Antonio Moreno Casamitjana
}

Estas palabras anhelan ser una memoria agradecida de don Antonio Moreno Casamitjana pronunciadas en nombre de la Facultad de Teología, a la cual estuvo vinculado la mayor parte de su vida. Don Antonio fue un hombre íntegro, sin dobleces. Un profesor de excelente calidad académica; un buen sacerdote y posteriormente obispo; pero sobre todo un creyente apasionado, que aprendió a confiarse en Dios en todos los momentos de su vida.

Comencemos recordando los grandes hitos de su vida ${ }^{1}$. Nació en Santiago el 9 de julio de 1927. Hijo de Antonio y María². Cursó sus estudios primarios y secundarios en el Instituto Alonso de Ercilla, de los Hermanos Maristas. En su juventud fue un activo participante de la Parroquia Nuestra Señora de Andacollo. Una vez concluidos sus estudios secundarios ingresó al Pontificio Seminario Mayor de Santiago, cursando sus estudios de teología en esta Facultad en los años 1945 a 1949, obteniendo al término de ellos el grado canónico de Licenciado en Teología ${ }^{3}$. Fue ordenado sacerdote en Santiago, el 4 de diciembre de 1949. El Papa Juan Pablo II lo designó obispo auxiliar de Santiago ${ }^{4}$, recibiendo la ordenación episcopal el 9 de julio 1986, al cumplir 59 años de edad. Tres años después fue nombrado Arzobispo de Concepción, servicio que ejerció hasta fines de $2006^{5}$. Falleció en Concepción el pasado 31 julio 2013, a los 86 años de edad.

\footnotetext{
Cf. Barrios Valdés, Marciano La Facultad de Teología de la Pontificia Universidad Católica de Chile. Sesenta años de historia al servicio de Chile (1935-1995). Santiago: Ed. Sociedad de Historia de la Iglesia en Chile 1995.

2 Ambos nacidos en España. Su padre nacido en Andalucía y su madre en Cataluña. Se conocieron en Chile y aquí contrajeron matrimonio.

3 Grado de Licenciado obtenido con fecha 26 abril 1950, siendo Decano el P. Ramón Echániz.

4 Designado Auxiliar de Santiago, y Obispo Titular de Mades, el 22 abril 1986.

5 Designado Arzobispo de Concepción el 14 octubre 1989, tomó posesión de la sede el 12 noviembre 1989. Fue aceptada su renuncia al cargo el 27 diciembre 2006, a la edad de 79 años y medio.
} 
Volvamos a los inicios, para dar una mirada a su recorrido académico. Concluida su formación en el Seminario partió a estudiar Sagrada Escritura en el Pontificio Instituto Bíblico de Roma, entre los años 1952 y 1955. Allí obtuvo el grado de Licenciado en Sagradas Escrituras, en 1955. El siguiente año académico lo dedicó a estudiar en la prestigiosa École Biblique de Jerusalén (1955-1956).

De vuelta en Chile, comenzó a trabajar inmediatamente como profesor de esta Facultad de Teología. En su primer nombramiento es designado como profesor de hebreo, a partir del 15 julio $1956^{6}$. Este es el inicio de su carrera docente en la Facultad. El 1 de mayo de 1958 fue designado Secretario de la Facultad, cargo que ejerció hasta 19617. En 1959 don Antonio asumió la dirección del programa de los cursos de la Teología para Laicos, en horario vespertino, con el cual se mantuvo activa y gustosamente comprometido hasta su nombramiento como Obispo Auxiliar de Santiago. Es decir, por casi 30 años. Estos cursos fueron una importantísima actividad de extensión teológica de nuestra Facultad, con la cual don Antonio se vinculó de corazón.

Durante sus primeros años como profesor tuvo además un estrecho nexo con el Pontificio Seminario Mayor de Santiago, donde ejerció la docencia, y en 1967 asumió como Vicerrector.

Entre 1958 y 1964 fue bibliotecario de la Facultad; y siempre se mantuvo muy atento a alimentar apropiadamente la biblioteca con buenos libros bíblicos. Fue director de la revista Teología y Vida (1964-1967) y de Anales de la Facultad de Teología (1960-1967). Fue Vicedecano de la Facultad entre los años 1965 y 1968 ${ }^{8}$. En 1968 fue ascendido a la calidad de Profesor Ordinario, equivalente a la actual categoría de Profesor Titular'. En 1970, obtuvo una beca para un trimestre de estudios de profundi-

$\overline{6}$ Decreto 310/56, del rector Mons. Alfredo Silva Santiago, 2 septiembre 1956.

7 Decreto 249/58, del rector Mons. Alfredo Silva Santiago, 16 junio 1958.

8 Asume como Vicedecano el 1 marzo 1965. Nombramiento del Gran Canciller, de fecha 18 febrero 1964 (¿1965?); y Decreto del Rector 19/65, de fecha 17 marzo 1965 (en otra copia, fechado el 24 marzo 1965). Todos ellos firmados por Mons. Alfredo Silva Santiago.

9 El 1 de agosto 1968 nombrado Ordinario/Titular por Decreto del Gran Canciller 33, del 26 agosto 1968, previo Nibil obstat de la Sagrada Congregación para la educación católica, del 12 julio 1968 (Prot 797/68). El 16 marzo 1967 había sido nombrado profesor Extraordinario/Asociado, por Decreto 66/67, previa aprobación dada por la Sagrada Congregación para Semina- 
zación sobre el profetismo en Munich, Alemania. Posteriormente ejerció como Decano de la Facultad por tres años, entre 1977-1979 ${ }^{10}$. Al ser nombrado Obispo Auxiliar de Santiago mantuvo la docencia en la Facultad, aunque reducida a pocas horas. Al partir a Concepción debió dejar todo vínculo con nuestra Facultad. Pero allí mantuvo la actividad docente en el Seminario Metropolitano de la Santísima Concepción.

Su actividad docente estuvo concentrada en la exégesis del Antiguo Testamento, y de modo especial en los ámbitos del Pentateuco y los Profetas. En ambos campos llegó a tener un conocimiento amplio y profundo de la exégesis histórico crítica, que daba el marco fundamental a su trabajo académico. Se puede decir que era un buen erudito en estas materias, con clases exigentes, en las cuales hacía pasar aprietos a sus alumnos. Pero, al mismo tiempo sabía desplegarse muy bien en una meditación más espiritual de los textos, que no se reflejaba tanto en sus clases, sino más bien en su predicación y en las actividades de difusión de la Biblia en grupos de fieles. Ya en la madurez, sus homilías como Arzobispo de Concepción fueron siempre una profunda y hermosa meditación de pasajes o temas bíblicos ${ }^{11}$.

rios y Universidades, con fecha 10 febrero 1967 (Prot 1860/60). El primer paso de su carrera académica había sido el nombramiento como "Profesor Docente» a partir de 1 marzo 1961 (Decreto 328/61 del rector Mons. Alfredo Silva Santiago, de fecha 8 agosto 1961), contando con el Nihil obstat de la Sagrada Congregación de Seminarios y Universidades, del 13 septiembre 1960 (Prot 1860/60). Nombramiento renovado el 23 marzo 1965, por Decreto 35/65; nuevamente renovado el 13 mayo 1966, por Decreto 148/66; y el 3 enero 1967, por Decreto 11/67.

10 Asumió como Decano el 20 diciembre 1976. Nombrado por Decreto del Pro Gran Canciller 39/76, de fecha 22 octubre 1976; previo Nibil obstat de la Sagrada Congregación para la educación católica, de fecha 21 octubre 1976 (Prot 797/68/12). El Prot 797/68/13, de fecha 1 diciembre 1976, de la misma Sagrada Congregación señala que este Nihil obstat se ha dado para subsanar una situación de hecho, datándolo en una fecha previa al nombramiento.

Estos fueron años de muchas tensiones entre el alumnado, la dirección de la Facultad, la Rectoría de la Universidad y la Conferencia Episcopal. Especialmente por la suspensión por un semestre de un numeroso grupo de alumnos, decretada por la rectoría, en el primer semestre de 1979. Ver detalles en Barrios Valdés, Marciano La Facultad de Teología de la Pontificia Universidad Católica de Chile. Sesenta años de historia al servicio de Chile (1935-1995). Santiago: Ed. Sociedad de Historia de la Iglesia en Chile 1995; pp. 131-133.

11 Los últimos meses de su vida los dedicó a preparar una edición de estos textos, en conjunto con la Universidad de la Santísima Concepción. Aún no se ha llegado a la edición de los textos. 
Sus escritos y publicaciones son muchos y variados. Publicó especialmente artículos exegéticos en la revista Teología y Vida, y otras afines. En los primeros años de la década de los 60 hay varios ar-tículos suyos en la revista Mensaje, atentos a una presentación de la Biblia para un público amplio que comenzaba a interesarse por ella; en tiempos aún pre-conciliares. Cabe recordar además sus muchas hojas de apuntes mimeografiados para complementar la docencia, tanto en la Facultad como en el Curso de Laicos. Mucho éxito tuvo su manual de Introducción a la Biblia elaborado en conjunto con otros dos profesores para el Programa de Educación a Distancia por medio de la TV (TELEDUC), iniciado en $1977^{12}$.

En estas épocas de su madurez como exégeta y teólogo asumió una multitud de responsabilidades más amplias. Fue miembro de la Pontificia Comisión Bíblica entre 1975 y 1986'13; y del Consejo de Redacción de la Revista Internacional Communio.

Además de sus actividades en la Facultad, don Antonio ejerció algunos servicios en el ámbito general de la universidad. Entre todos ellos cabe destacar que en reiteradas oportunidades como Gran Canciller subrogante y finalmente fue designado Vice Gran Canciller ${ }^{14}$. Fue integrante del Honorable Consejo Superior, en representación de los docentes ${ }^{15}$; y miembro de la Comisión de Ética de la UC. Esta misma Universidad le confirió el Grado Académico Honorífico de Doctor Scientiae et Honoris Causa, en $1988^{16}$.

En sus tiempos como profesor de la Facultad, don Antonio siempre mantuvo una actividad apostólica, prestando servicios pastorales en pa-

12 Moreno Casamitjana, Antonio; Moreno Garrido, Jaime; Villegas Mathieu, Beltrán Introducción a la Biblia: curso de iniciación teológica. Santiago: Pontificia Universidad Católica (TELEDUC) 1975. 226 pp.

13 Su primer nombramiento en la Pontificia Comisión Bíblica es del 9 septiembre 1975 , por un período de 5 años, que luego fue renovado para un segundo período.

14 Varios períodos entre los años 1977-1981, reemplazando a Mons. Jorge Medina. Cf. Decretos del Pro Gran Canciller 14/77, del 2 junio 1977; 23/78, del 12 diciembre 1978; 48/79 del 5 diciembre 1979; 28/80, del 1 diciembre 1980. Es nombrado Vice Gran Canciller el 19 marzo 1982, por Decreto Gran Cancillería 37/82.

15 Cf. Decreto de Rectoría 41/84, del 16 abril 1984; y Decreto Rectoría 34/85, del 2 abril 1985. Es designado hasta el 28 enero 1987.

16 El Grado le fue otorgado en la sesión del Consejo Superior del 3 junio 1988. Formalizado mediante el Decreto de Rectoría 102/88, del 14 de junio 1988. Le fue entregado en un acto solemne el 30 de noviembre de 1988. 
rroquias de sectores populares. Entre ellas la parroquia San José Obrero (Población Cardenal Caro) y la parroquia San Diego (Conchalí). Movido por un genuino impulso apostólico y una cariñosa cercanía a los más sencillos, durante más de un decenio, en los años finales de su presencia como profesor en la Facultad tuvo una curiosa modalidad de trabajo: durante un semestre se dedicaba a la docencia a tiempo completo, y el otro semestre lo dedicaba al trabajo apostólico sirviendo en la parroquia de Rolecha, diócesis de Puerto Montt.

Dentro de este elenco de datos más objetivos de los vínculos de don Antonio con nuestra Universidad, cabe señalar finalmente que siendo Arzobispo de Concepción y ante el inminente cierre de la sede regional de Pontifica Universidad Católica de Chile, tomó la decisión de crear la Universidad de la Santísima Concepción, la que estableció por decreto del 10 julio 1991. Por lo mismo, fue su primer Gran Canciller, desde esa fecha para su renuncia como Arzobispo.

Concluidos estos datos más objetivos, es apropiado tratar de entrar en la interioridad más personal de don Antonio. Me permito hacer mías las palabras pronunciadas por Mons. Jorge Medina, su contemporáneo y amigo, en el acto solemne de entrega del doctorado Honoris et Scientiae causa $^{17}$.

«¿Una semblanza de Antonio Moreno? Tarea a la vez fácil y difícil. Fácil porque los rasgos de su acusada personalidad son definidos: no es un hombre que deja dudas o incertidumbre; tal vez no haya característica más opuesta a él que la ambigüedad. Hombre de una pieza, de pensamiento claro y definido. Sabe lo que es matizar, pero sabe también decir sin ambages lo que piensa, así no haya a su lado nadie que lo apoye. Pero no es fácil penetrar en el interior de Antonio, porque es un hombre reservado, modesto, muy ajeno a hablar de sí mismo. Los que lo conocemos y somos sus amigos intuimos que detrás de su exterior sencillo, franco y jovial, se esconde un mundo interior rico e insospechado. ¿Quién de los que lo hemos tratado no ha percibido la paradoja de ese hombre de risa franca y generoso en su amistad, y al mismo tiempo solitario como los picachos rocosos de nuestra cordillera que le son tan familiares?

Publicado en Anales de la Facultad de Teología, volumen 39, 1988, Anunciaré tu verdad. Homenaje a los profesores Antonio Moreno y Beltrán Villegas. p. 29 
Antonio es un sacerdote. El nervio pastoral lo recorre entero y lo perciben a flor de piel lo que reciben el servicio desinteresado de su ministerio. Silenciosamente va formando cristianos, tratando de dejar en ellos la huella del Maestro. Un día tuvo la ocurrencia de ir a misionar a Rolecha, en los confines de Chile continental. Y allá recorrió poblados predicando, celebrando los sacramentos, formando catequistas, estableciendo comunidades cristianas. Lo hizo, como siempre, silenciosamente. Con frío, con lluvia, alojando donde se pudiera en los largos recorridos de esa parroquia de más de cien kilómetros de largo».

No es fácil entrar en la interioridad de don Antonio. En el discurso de agradecimiento del doctorado honorífico recuerda que desde la primera tonsura, inicio del proceso ministerial, hasta su ordenación episcopal ha usado como lema una frase del Salmo 89, que él reproduce allí como "Anunciaré tu 'emunah de generación en generación». Luego se dedica a explicar que 'emunah es una palabra que se presta a un doble sentido: puede ser traducida como verdad o como fidelidad. Este dato de erudición exegética le permite entrar en un comentario espiritual que me parece muy revelador de sus planteamientos más profundos ${ }^{18}$.

«Esa posibilidad de doble sentido me sedujo. Doble sentido no quiere decir ambigüedad, sino que significa que si Dios nos ha hecho capaces de buscar la verdad es para que nos dejemos atraer por ella sabiendo -nosotros los cristianos- que al final nos vamos a encontrar con la fidelidad de Dios que nos atrae a la vida. Y para que entendamos, por otra parte, que es solamente el amor de Dios el que puede sostener nuestra búsqueda de la Verdad que encamina a la Vida».

Y explicando más concretamente el porqué de la elección de esta frase como su lema episcopal señala: «Después de haber recibido el sacerdocio con el temor que, para tranquilidad mía, ya habían experimentado Moisés, Josué y los profetas, ese temor que no se supera si no es por la garantía de que Yahveh asegura su presencia, ahora, a estas alturas de la vida sentía que no podía hacer otra cosa que anunciar la fidelidad de Dios, que ha cubierto todas las infidelidades mías».

Finalmente me permito algunos recuerdos más personales, a partir de mi propio conocimiento de don Antonio. Mi primer encuentro con él fue en el año 1968, al iniciar mis estudios teológicos, en la vieja casa

$18 \quad$ Ibid. p. 27. 
de la Facultad, en la Alameda. En ese momento, don Antonio vivía en los locales de la Facultad, junto a otros profesores. De verdad la Facultad era su casa, en sentido fuerte. Me impresionó la imagen de profesor sabio, pero en esos años sometido a presiones fuertes que lo hacían sufrir mucho. Eran los tiempos de la reforma universitaria y del inicio del primer rector laico de la UC, don Fernando Castillo Velasco. En nivel más interno de la Facultad eran tiempos de una profunda reforma curricular en la Facultad, coincidente con el inicio del decanato del P. Juan Ochagavía, de cambios en la composición del alumnado y la admisión de los primeros estudiantes laicos, hombres y mujeres ${ }^{19}$. Cambios tan hondos conllevaban muchas ambigüedades y tensiones, cosas que a don Antonio lo inquietaban profundamente. Pero al mismo tiempo, esas tensiones lo llevaron a entrar en un agudo estudio de los profetas bíblicos, que fue decantando posteriormente en muy buenos artículos publicados en Teología y Vida. Este serio profesor tenía una espléndida moto, de gran cilindrada, que usaba habitualmente ${ }^{20}$. Con el paso de los años, la moto se transformó en una más modesta bicicleta usada diariamente para llegar a la Facultad. Al mismo tiempo era un experimentado montañista, del cual se rumoreaba conocía muy bien el Aconcagua. Algunos alumnos aventajados en esta área compartían sus salidas de fin de semana por la cordillera cercana a Santiago. Todos los de aquella época recordamos bien sus buenas clases, aunque fueran muy exigentes, y a veces excesivamente técnicas. Y también el modo algo radical con que planteaba los resultados de la exégesis histórico crítica, con los cuales producía más de algún sobresalto en algunos alumnos.

Muchos años después tuve la gracia de interactuar bastante con él en su calidad de Arzobispo de Concepción, estando yo en responsabilidades propias de mi comunidad religiosa. En este tiempo pude conocer al pastor sencillo, servicial, atento a la vida y necesidades de las personas. A veces algo tenso en los actos formales, o en los momentos de conflicto, pero siempre relajado y cariñoso cuando conversaba con la gente sencilla; al

19 Cf. Barrios Valdés, Marciano La Facultad de Teología de la Pontificia Universidad Católica de Chile. Sesenta años de historia al servicio de Chile (1935-1995). Santiago: Ed. Sociedad de Historia de la Iglesia en Chile 1995; pp. 85-97.

20 Se trataba de una gran moto BMW, comprada por don Antonio en su tiempo de estudiante en el Pontificio Instituto Bíblico de Roma, luego la llevó a Israel para sus tiempos de estudio en la École Biblique de Jerusalén, y finalmente la trajo a Chile. La conserva hasta hoy su hermano José Moreno Casamitjana. 
punto que perdía la noción del tiempo; lo vi quedarse por horas conversando animadamente con grupos de parroquias populares, en torno a una taza de té y un queque.

Estas pequeñas descripciones nos ayuden a agradecer a Dios por la vida de monseñor Antonio Moreno, don de Dios para esta Facultad de Teología. Tanto en su condición de profesor exigente y bien formado, como en su actividad de pastor bondadoso, a quien las formalidades y las ambigüedades le costaban mucho y lo hacían entrar en tensión, pero que mostraba todo su corazón y su calidad espiritual cuando podía entrar en un diálogo de honda raíz humana. Gracias también a su familia, que lo formó y acompañó, representada en sus hermanos que hoy nos acompañan.

\section{Publicaciones}

«El misterio de la Palabra de Dios» en Teología y Vida 1 (1960) 21-28. «Jesús, ¿̇admite el divorcio?» en Teología y Vida 1 (1960) 101-106. «La historia, en el Antiguo Testamento, género literario» en Teología y Vida 2 (1961) 162-167.

«Para una lectura cristiana de la Biblia» en Teología y Vida 2 (1961) 235-243. «Una polémica sobre la moderna exégesis católica» en Teología y Vida 2 (1961) 183-186.

«La Biblia frente a la ciencia» en Mensaje 1961, pp. 140-145.

«El mito de Jesús» en Mensaje 1961, pp. 469-476.

«Amós. Una presentación exegética» en Teología y Vida 4 (1963) 23-35.

«La paz en la Sagrada Escritura» en Mensaje 1963, pp. 215-222.

«Génesis 1,1 - 2,4a» en Teología y Vida 5 (1964) 36-44.

«Génesis 2,4b - 2,24» en Teología y Vida 5 (1964) 207-222.

«Acerca de las relaciones con los judíos» en Teología y Vida 8 (1967) 313-319.

«Jesús ben Sira. Un judío en tiempos de crisis» en Teología y Vida 10 (1969) $24-42$.

«Jeremías. La política en la vida de un profeta» en Teología y Vida 12 (1971) 187-208.

«Falsos profetas en el Antiguo Testamento» en Teología y Vida 14 (1973) 129-148. «El misterio de la unidad en los relatos patriarcales» en Teología y Vida 14 (1974) 258-280.

Moreno Casamitjana, Antonio; Moreno Garrido, Jaime; Villegas Mathieu, Beltrán. Introducción a la Biblia: curso de iniciación teológica. Santiago: Pontificia Universidad Católica (TELEDUC) 1975. 226 pp. 
«André Neher. La esencia del profetismo» en Teología y Vida 18 (1977) 61-69. «Significado de la sexualidad en el Antiguo Testamento» en Teología y Vida 18 (1977) 251-268.

«Génesis 2,46 - 3,24. Estudio de método exegético» en Teología y Vida 19 (1978) 259-278.

«Fe y cultura en el Antiguo Testamento» en Teología y Vida 19 (1978) 3-24.

«La exégesis de Génesis 2,48 - 3,24. Problemas de método» en Teología y Vida 19 (1978) 259-278.

«Facultad de Teología. Organismos y actividades» en Teología y Vida 19 (1978) 129-134.

"¿Es fácil o difícil leer la Biblia? en Teología y Vida 20 (1979) 3-14.

Moreno Casamitjana, Antonio; Moreno Garrido, Jaime; Villegas Mathieu, Beltrán. Interpretar la Biblia. Santiago: Editorial Salesiana 1978. 179 pp.

«El matrimonio y la familia en el Antiguo Testamento. IV Jornadas Chilenas de Derecho Natural» en Revista de Derecho 7 (1980) 525-566.

[En colaboración] Comentarios Encíclica Redemptor Hominis. Santiago: Editorial Salesiana 1980. 95 pp.

«Tarea y destino del hombre según el Antiguo Testamento» en Teología y Vida 23 (1982) 87-102.

«Pecado y conversión en el Antiguo Testamento» en: Anales de la Facultad de Teología 33 (1982) 33-62.

«Acerca de la paz y violencia en el Antiguo Testamento» en Teología y Vida 25 (1984) 3-22.

«El Pueblo de Dios en el Antiguo Testamento» en Teología y Vida 26 (1985) 5-29.

"Acerca de la interpretación de la Biblia» en Revista Universitaria 16 (1985) 48-57.

[Varios] Anunciaré tu verdad. Homenaje a los profesores Antonio Moreno y Beltrán Villegas. Santiago: Anales de la Facultad de Teología 39, 1988. 329 pp.

[Varios] Annuntiaboveritatemtuam. Estudios en homenaje a Monseñor Antonio Moreno Casamitjana. Santiago: Universidad Católica de la Santísima Concepción 2009. 453 pp.

"Anunciaré de generación en generación tu verdad (Sal 89, 2B)» en Anales de Teología (Concepción) 12 (2010) 393-400. 
